\title{
ENTRE EL DECADENTISMO Y EL CRIOLLISMO: EL CASO DE "LOS OJOS DE JUDAS" DE ABRAHAM VALDELOMAR
}

\author{
BETWEEN DECADENTISM AND CRIOLLISMO: THE CASE \\ OF "LOS OJOS DE JUDAS" BY ABRAHAM VALDELOMAR
}

\section{JORGE VALENZUELA GARCÉS*}

\section{RESUMEN}

En este artículo estudiamos las complejas relaciones entre ciertos componentes decadentistas, propios de la herencia modernista, y aquellos de la poética criollista, ambos presentes en "Los ojos de Judas" de Abraham Valdelomar. Postulamos que, en el caso de este cuento, es posible identificar una narrativa heterogénea que se pretende nacional a partir de la reivindicación de lo local, pero que a su vez no abandona los rasgos propios del modernismo decadentista como la exploración en el mal, la enfermedad y el cuestionamiento de los valores del cristianismo. Realizamos el análisis del cuento a partir de la comparación de las poéticas decadentista y criollista, a la que sumamos una aproximación al texto que se apoya en el análisis de la perspectiva narrativa, los roles actanciales y las relaciones intertextuales que establece el cuento.

Palabras clave: Abraham Valdelomar, "Los ojos de Judas", narrativa criollista, decadentismo, cuento peruano.

\section{ABSTRACT}

In this article we study the complex relations between certain decadent components, typical of the modernist heritage, and those of the criollista poetics, both present in Abraham Valdelomar's "Los ojos de Judas" ("The eyes of Judas"). We postulate that, in the case of this tale, it is possible to identify a heterogeneous narrative that claims to be national on the basis of the recovery of what is local, but which in turn does not aban-

* Doctor en Literatura Hispanoamericana por la Universidad Complutense de Madrid. Actualmente es Director del Departamento de Literatura de la Facultad de Letras de la Universidad Nacional Mayor de San Marcos en Lima, Perú. Correo electrónico: jorgevalenzuela4@hotmail. com 
don the features of decadent modernism such as exploration of evil, disease, and the questioning of the values of Christianity. We perform the analysis of the story from the comparison of decadent and criollista poetics, to which we add an approach to the text that is based on the analysis of the narrative perspective, actantial roles and intertextual relations established by the story.

Keywords: Abraham Valdelomar, "Los ojos de Judas", criollista poetics, decadent poetics, Peruvian short story.

Recibido: 24.05.17. Aceptado: 26.02.18.

\section{EL PUNTO DE VISTA Y LOS ROLES ACTANCIALES EN "LOS OJOS DE JUDAS"}

\subsection{El narrador y la perspectiva narrativa en "Los ojos de Judas"}

$\mathrm{E}$ N "LOS OJOS DE JUDAs", el narrador es un adulto que recuerda hechos trágicos, experiencias traumáticas vividas en su niñez. No es, entonces, en sentido estricto, un niño el que recuerda y, menos aún, el que narra. El acto de la enunciación establece una distancia mediada no solo por el tiempo verbal que se emplea para decir las cosas, sino por la manera en que son dichas, propias de un adulto que procesa y filtra el recuerdo a través del lenguaje. El cuento presenta un primer nivel extradiégetico en el que el narrador presenta los hechos situándose a una distancia de ellos. Digamos que este nivel sirve como marco para insertar al lector, a través de estrategias persuasivas, en el centro de los hechos, pero no en los hechos mismos.

El nivel de la narración pasa a ser intradiégetico cuando el narrador acorta la distancia mediada por el recuerdo y, como si se tratara de un relato contado por un niño, nos sitúa en medio de los acontecimientos. El narrador es autodiegético, pues se narran los acontecimientos desde un personaje que ha asumido la condición de protagonista de los mismos y que, por lo tanto, es parte del mundo representado. En esta dirección, la narración autodiegética conducida por un adulto que busca recuperar recuerdos de su niñez cumple con algunas funciones: La primera es subjetivizar la narración, es decir, hacerla más personal; la segunda, transitar de manera espontánea e inocente por el entorno natural con el objetivo de que los eventos sean percibidos con la puerilidad propia de un niño y, la última, atender, desde la conciencia piadosa de un niño, las relaciones intra y extrafamiliares. Un narrador de estas características contribuye a que los hechos 
sean percibidos, aparentemente, sin ninguna carga ideológica, aunque la carga moral del cristianismo sea dominante precisamente porque ese tipo de carga lo es cuando se tiene nueve años.

El adulto que recuerda lo hace a partir del movimiento evocativo en el que impera la belleza del entorno para un niño, pero también lo extraño. En ese sentido, la historia contada no puede dejar de complejizar la pretendida "tranquilidad" pueblerina y cuestionar "el encanto de la aldea" que, a partir de los hechos recordados, se ha perdido para siempre en la memoria del personaje narrador.

En "Los ojos de Judas" estamos frente a un relato focalizado internamente desde la conciencia de un personaje (que es a la vez el narrador) cuya subjetividad se corresponde con la de un hombre adulto que se ve a sí mismo, cuando niño, viviendo una experiencia trágica. Sin embargo, esta focalización se combina en el cuento con la externa en los momentos en los que el personaje narrador se ocupa de la descripción del entorno. A partir de esta doble focalización, el relato nos permite asistir a un movimiento pendular en el que el entorno natural se convierte en un escenario activo, cuya participación es decisiva en la historia. Otra característica de la focalización en este relato es el ser fija, porque no se abandona nunca la visión del personaje-narrador, la misma que a lo largo del relato se mantiene constante y nos permite alcanzar una visión unitaria de lo acontecido.

\subsection{Personajes y roles actanciales en "Los ojos de Judas"}

Destaquemos, en principio, a dos como los personajes principales del cuento: Luisa/la mujer blanca ${ }^{1}$ y el personaje narrador que es innominado. Luego tenemos a los personajes secundarios: el padre y la madre del personaje narrador que, en un diálogo, informan sobre la tragedia que atraviesa Luisa y, como personajes episódicos, a Fernando, autor del asesinato y Kerr, la víctima. Como figurantes tenemos a los pobladores de Pisco que realizan actividades en el pueblo y durante las festividades de la Semana Santa.

Una de las características de los personajes principales de "Los ojos de Judas" es el ser dinámicos. En el caso de Luisa, observamos un cambio que supone el abandono de su primera identidad para devenir en la mujer blanca. Esta transformación no explicitada, pero deducible por los aconte-

\footnotetext{
${ }^{1}$ La blancura es uno de los elementos que Valdelomar trabaja en los cuentos criollos para caracterizar a sus singulares y extrañas mujeres. Véase el caso del personaje Glicina en "El hipocampo de oro" en donde es descrita como "la única mujer blanca entre los pobladores indígenas".
} 
cimientos, tiene lugar después de la traición a su esposo y la desaparición de su hijo, dos hechos que precipitan su cambio. Las formas de aparición de Luisa/la mujer blanca concentran su nueva identidad. Estas se dan siempre de manera misteriosa y tienen lugar en un espacio (la orilla del mar) que sirve como límite simbólico entre dos mundos: la vida, representada por el pueblo, y la muerte, representada por el mar. Es más, su nuevo aspecto tiene como propósito vincularla con la pureza, pero también con la muerte. Citemos: “¡Era tan blanca! Sus facciones afiladas parecían no tener sangre; su mirada era húmeda, amorosa y penetrante" (Valdelomar, 2013, p. 179).

De otro lado, la naturaleza dinámica del personaje narrador se advierte en el cambio psicológico que se opera en él hacia el final del relato, después del suicidio de Luisa/la mujer blanca. Su férrea resistencia a otorgarle el perdón a Judas cesa al final y se aviene a perdonar al bíblico criminal y, por ende, a la esposa traidora. Este cambio dramático supone un proceso de aprendizaje en quien se ve motivado a ser más flexible ante el horror de la muerte.

Si bien el propio narrador no se describe a sí mismo, son las acciones que realiza las que lo caracterizan. De este modo sabemos que es un niño piadoso de nueve años cuya fragilidad ante los sucesos lo precipita en el llanto y que su vocación por la soledad lo conduce por las costas de Pisco experimentando la extraña belleza del entorno. Es, en suma, un niño solitario cuya profesión de fe lo ha convertido en un creyente que respeta la ortodoxia de los dogmas de la religión cristiana. Citemos: "Sentí los sollozos de mi madre. Asustado, me cubrí la cabeza con la sábana y me puse a rezar, inconsciente y temeroso, por todos esos desdichados a quienes no conocía" (2013, p. 175).

De acuerdo al esquema narrativo descrito líneas arriba, es posible advertir en el relato la frustración de Luisa/la mujer blanca en el propósito de conseguir, en vida, su objeto de valor: el perdón. La lucha por la obtención de este objeto genera una confrontación entre Luisa/la mujer blanca (destinadora y destinataria del objeto) y el personaje narrador (oponente) en el intento de lograr la posición dominante en la disputa. Esta confrontación, ciertamente, compromete los valores del cristianismo y, como se ve hacia el final del relato, supone una flexibilización de las posiciones radicales del narrador con respecto a Judas y la traición. En efecto, si bien este logra una posición dominante al negar el perdón a Judas y, por lo tanto, a la esposa felona, vemos que al final del relato, luego del suicidio de Luisa/la mujer blanca, se produce su arrepentimiento. Es evidente que este cambia su punto de vista y con ello pasa a reconsiderar la imagen del apóstol traidor. 
Como destinadora-destinataria, Luisa/la mujer blanca logra la competencia modal al presentarse, después de perder la razón ${ }^{2}$, como una mujer cuya "apacible mirada", cuya pureza representada por el color blanco de su vestimenta y amorosa sensibilidad, logran ganar la simpatía del personaje narrador. Sin embargo, esta competencia no será suficiente para conseguir su objeto de valor, pues solo al morir, es decir, solo con la muerte es que logrará su objetivo.

Sin posibilidades de vivir el perdón y así lograr la salvación cristiana, las acciones conducen a Luisa/la mujer blanca a su autodestrucción. La sucesión de acontecimientos violentos, en medio del conservadurismo piadoso que vive el pueblo, cierra cualquier posibilidad de renovación personal y social y más bien conduce al pueblo a afirmarse en el atavismo de ciertas costumbres de profundo arraigo religioso. Este hecho se confirma a través de la sanción final que recibe Luisa/la mujer blanca quien, al fracasar en el intento de conseguir el perdón por la traición cometida, procede a suicidarse.

En suma, el cuento, a través de la mujer blanca (que podemos imaginar como la transfiguración de Luisa en busca de su hijo), pugna por hacer de Judas una figura digna del perdón, lo cual implica una búsqueda extrema de su propia redención en un contexto en donde ese perdón se hace imposible. Esta exigencia de perdón es un objeto de valor que ella busca para Judas y para sí misma en el entendido de que su traición ha estado condicionada por la salvación de su hijo.

\section{HACIA UNA LECTURA DECADENTISTA DE "LOS OJOS DE JUDAS"}

De acuerdo con la crítica, la primera etapa de la narrativa de Valdelomar, aquella ortodoxamente decadentista en la que escribe La ciudad de los tísicos. (La correspondencia de Abel Rosell) y La ciudad muerta. Por qué no me casé con Francinette se extiende a los años 1910 y 1911. 1912 es, pues, el año decisivo, aquel en que se produce una interesante reconsideración o enriquecimiento del modernismo decadentista que venía profesando bajo la influencia de autores como D’Annunzio y Wilde. Bajo esta influencia,

\footnotetext{
${ }^{2}$ Recordemos que la pérdida de la razón de Luisa se produce al enterarse de que le habían robado a su hijo. Es el padre del narrador, en diálogo con su esposa, quien le dice que cuando trasladaban el cadáver de Kerr "se promovió un gran tumulto (...) fuimos hacia allí y hemos visto a Luisa gritar, mesarse los cabellos y, como loca, llamar a su hijo. ¡Se lo habían robado!”. Desde ese momento Luisa desaparece y hace su misteriosa aparición "la mujer blanca.
} 
Valdelomar cuestiona los fundamentos de la razón, realiza una exploración inusitada de los sentidos (o un acercamiento a una realidad usualmente imperceptible), y explora en la enfermedad, la cual es tratada en sus textos como si los personajes se encontraran ante un objeto digno de generar reflexiones profundas. Cuando aparece la figura del artista en estos relatos, este se confronta con el mundo a través del arte como su única tabla de salvación. Pero también están presentes lo extraño, lo onírico, lo perverso y lo abismal. El elemento culto no está ausente, sobre todo en los cuentos. En ellos se hace una variada referencia a ciudades y personajes de la historia universal mostrando ese idealismo universalista del que hacían gala los modernistas. En lo que sigue analizaremos la influencia del modernismo decadentista en "Los ojos de Judas" y cuestionaremos su carácter criollista.

\subsection{El sentido de lo marginal y perverso en "Los ojos de Judas"}

Como en la narrativa decadentista, en "Los ojos de Judas" se experimenta el llamado repliegue espiritual que suspende el presente (que se percibe como adverso e insoportable) para instalarnos en un ámbito portuario como Pisco "en donde todo era bello y memorable" (2013, p. 170). Este repliegue establece una distancia que sirve para la construcción de un tiempo y espacio mentales a través del recuerdo. Este movimiento de la memoria que busca inmovilizar el presente a través de la instalación del pasado ancla, sin embargo, al que recuerda, en una dimensión de la que es imposible esperar alguna clase de sosiego, regeneración o salida, sobre todo si lo que se recuerda es un hecho trágico. El cuento, en ese sentido, apenas sí puede escapar del horror empleando el recurso de las descripciones del paisaje que se constituyen en los únicos respiraderos (recordemos la importancia de la orilla desde la que se puede tener una distancia de los hechos) a los que acude el narrador para soportar el permanente recuerdo doloroso.

La elección de Judas (su historia posee los elementos de la ruina moral y la muerte) como eje central en el relato, sitúa de lleno al cuento en la estela del decadentismo al convocar a lo oscuro y al mal y al actualizar una vieja narrativa, la de la traición, pero sobre todo al tratar de postular una nueva interpretación de este acto condenable. El cuento, en este sentido, se postula sobre todo como un esfuerzo desde lo estético que busca fundar una ética propia a través del arte. Esta búsqueda que se gesta a partir de la exploración en la subjetividad y en la experimentación de sensaciones extrañas y percepciones ambiguas tiene como telón de fondo una historia trágica, la de Luisa/la mujer blanca cuya traición la homologa al propio Judas. 
El primer elemento decadentista que articula la historia en "Los ojos de Judas" es la elección de un personaje como Luisa/la mujer blanca cuya actuación la sitúa, problemáticamente, al margen de lo permitido, como al propio Judas de la tradición cristiana. En esta dirección, el relato de los hechos construye un recorrido narrativo que busca la inversión de los valores establecidos por la moral social del cristianismo con el propósito de conseguir el perdón para una traidora y, por ende, para Judas. Esta postura transgresora, al final triunfante, es propia de la poética decadentista que opta por convertir en natural o posible lo que se encuentra condenado por los dogmas de la religión o la moral.

Incluso un estado como la pérdida de la razón en Luisa/la mujer blanca es sublimado en el cuento a partir de imágenes asociadas a la santidad y a la blancura que irradia al momento de aparecer en aquellos estados intersticiales de sueño-vigilia del personaje narrador. En efecto, la insania es presentada en el cuento a través de un proceso de espiritualización y pureza que busca hacer positiva la enfermedad de Luisa/la mujer blanca al mostrarla como portadora de buenos sentimientos. Incluso su autoeliminación, que produce el horror final en el personaje narrador, es valorada por él como una inmolación a favor del perdón de Judas. La reivindicación de este antihéroe gestada desde los extremos de una insoportable culpa, dota al cuento de una nueva lectura del mal y de sus efectos sobre los seres humanos.

De otro lado, el tratamiento de lo transgresor se visibiliza en el cuento desde el título con la elección de un personaje como Judas, cuyo significado, dentro de la narrativa cristiana, evoca la traición y el suicidio ${ }^{3}$. Si bien el cuento no defiende al traidor de manera desafiante ni soberbia, sí busca la identificación final del narrador personaje con la figura de Judas. Citemos el pasaje final en que se produce su conversión: “-¡Sí, perdono a Judas señora blanca, sí, lo perdono!...” (2013, p. 184). Es cierto que el perdón llega hacia el final, pero luego de un trayecto marcado por un profundo sentimiento de culpa (central en el relato) experimentado por Luisa/ la mujer blanca en el contexto de las celebraciones de semana santa en que se actualiza la dramática agonía de Jesucristo. Ese es el marco general que enrarece los acontecimientos y en el que es posible que un joven piadoso pueda tener conversaciones con una mujer singular cuya bondad lo fascina a pesar de su halo misterioso y hasta milagroso. En efecto, despojada de

\footnotetext{
${ }^{3}$ La historia de Judas recogida en los evangelios se constituye en el hipotexto a partir del cual se ofrece una relectura de la traición a Jesucristo.
} 
su cotidiana apariencia y convertida en otra, esto es, dueña de una nueva identidad, Luisa puede tentar al perdón de Judas y al suyo propio. Para ello le sirve la medalla de la Virgen Purísima que deja en el bolsillo del narrador personaje y los gestos de protección que traducen un amor filial hacia él.

El tratamiento hiperbólico de los ojos de Judas, hacia el final del texto, sirve al propósito de construir una estética de lo grotesco que se opone, en principio, a la sublime y santificada imagen de Luisa/la mujer blanca. Citemos: "Llegué al sitio en donde Judas, en medio del pueblo, se elevaba, pero le tenían cubierto con una tela y solo se le veía la cabeza. Tenía dos ojos enormes, abiertos, iracundos, pero sin pupilas y la inexpresiva mirada se tendía sobre la inmensidad del mar" (2013, p. 179). Luego, esos mismos ojos y mirada se homologarán a los de la mujer blanca después de su suicidio. El carácter transitivo de la mirada del traidor es un mecanismo que une a Judas, a la mujer blanca y al personaje narrador. Citemos: "Creí que el cadáver me miraba, que me reconocía; que Judas ponía sus ojos sobre él..." (2013, p. 184) y "yo, con los ojos muy abiertos, vi mientras que mi padre me llevaba, rojos y sangrientos, acusadores, siniestros y terribles, los ojos de Judas que miraban por última vez..." (2013, p. 184).

Este es el elemento que precipita el terror psicológico experimentado por el niño en contacto con el cadáver de Luisa/la mujer blanca, varada por las aguas con los ojos muy abiertos (parecidos a los del muñeco de Judas que van a quemar en la plaza en sábado de gloria). Este elemento nos acerca a lo oscuro, a la manifestación material del mal.

\subsection{La familia en cuestión: el fin de la estirpe}

Si bien la poética criollista obvia el horizonte político explícito y por ello no se visibilizan las contradicciones sociales, no estamos totalmente de acuerdo con Bernabé cuando sostiene que, en "Los ojos de Judas", "la dimensión mítica elimina la contingencia tanto en el ámbito del hogar como en el de la aldea" (2006, p. 48). En realidad, el cuento explota lo contingente al incorporar una serie de acontecimientos que van afectando dramáticamente el desarrollo de la trama que articula, sobre todo, las relaciones familiares. En este sentido, en toda la primera parte del cuento (los cuatro primeros bloques) se da paso a la demolición del núcleo familiar a partir de dos hechos trágicos: el encarcelamiento de Fernando, luego de que este asesinara a Kerr por una vieja cuestión de honor, y la traición cometida por Luisa, su esposa, al delatarlo como autor del crimen, hecho que se produce, ciertamente, bajo la amenaza de ser despojada de su hijo. Para asegurar la destrucción total de la fa- 
milia, en el cuento se consuma la pérdida del hijo que, como un castigo a su traición, precipita a Luisa en la locura. Todos estos hechos rompen con la posibilidad de imaginar una familia unida y mucho menos de recordarla en esos términos. Esto es lo que sucede con el narrador quien, incluso, cuando recuerda a su propia familia, se ve conmocionado por el dolor. De hecho, ambas familias, la del personaje narrador y la de Luisa sufren, progresivamente, un proceso de invisibilización a lo largo del cuento que termina centrándose en el destino individual del personaje narrador y de Luisa. Pero es cierto que la aparición de la mujer blanca en el cuarto bloque le otorga al relato una dimensión sobrenatural y extraña.

En un primer momento, asistimos al malestar experimentado por el personaje narrador dentro de su propia familia debido a la ausencia del padre cuyas obligaciones laborales (es empleado de la aduana) lo alejan todo el tiempo del calor familiar. Esta ausencia, que produce en su esposa desasosiego y tristeza, se extiende a lo largo del relato y se manifiesta en momentos como la hora de la cena o las celebraciones por Semana Santa. Luego, la llegada de la noticia del asesinato cometido por Fernando precipita al narrador en la angustia, que lo hace refugiarse en el rezo ante el sufrimiento de sus padres.

Con respecto a la familia es posible sostener, además, que el cuento presenta al estrato de clase media con modos y costumbres bastante tradicionales y sofisticadas. Recordemos la ceremonia de la cena en la casa del narrador personaje, asistida por una criada, y ciertos detalles que la convierten en un acto casi eclesial. El detalle de la servilleta del padre ausente "doblada en el aro, con su cubierto reluciente y su invertida copa" es suficiente para mostrarnos el perfil aristocratizante de la familia y la severa distancia frente a lo que podría denominarse genéricamente popular. Desde este espacio social las propuestas de modernización se tornan ambivalentes sobre todo cuando el horizonte ideológico en el que discurren sus integrantes está poblado del conservadurismo religioso. En ese sentido resulta revolucionario que el narrador, hacia el final del cuento, rompa con la tradición cristiana y acepte perdonar a Judas, hecho que, aunque gestado por el horror de la muerte de Luisa, resulta inusitado.

\subsection{Dilemas éticos y heroísmos sin esperanza en "Los ojos de Judas"}

El principal dilema que plantea "Los ojos de Judas" es que el apóstol traidor, Judas, pueda ser perdonado (a instancias de una traidora como Luisa/la mujer blanca) por un niño respetuoso de los principios de la religión católi- 
ca y las enseñanzas familiares. Aunque este dilema puede ser comprendido en los términos de la oposición entre un discurso moderno y emancipador que busca la autonomía del sujeto (incluso cuando se produce, como en el caso de Judas, una traición) y otro, que se consolida desde la culpa (ser todos pecadores) a partir del respeto del dogma cristiano, debe tenerse en cuenta que estamos ante las realizaciones de la poética del decadentismo narrativo que no plantea una renovación ideológica desde la modernidad, ni se abre a los vientos del cambio. ¿Cómo entender esta propuesta cuestionadora del dogma desde el decadentismo?

La moral del decadentismo se manifiesta en "Los ojos de Judas" a partir de dos elementos: la reivindicación final de Judas y por ende de la traición, es decir, el triunfo final del mal, visible en el perdón final otorgado a Judas por el personaje narrador, y la pérdida total de esperanza de Luisa/la mujer blanca cuyo suicidio confirma, desde su condición de madre, la clausura de la renovación social.

Estos dos elementos confirman la ética desde la que se articula el decadentismo narrativo y consolidan la ruina moral que se expande por todo el relato.

Con respecto al primer elemento, la sustitución del buen proceder (ser leal) por un comportamiento anético (defender al traidor), carente de sustento en un universo normado por el respeto al otro, condena al personaje narrador a ser parte de ese universo transgresor. Sin embargo su transformación final, al otorgar el perdón a Judas bajo la imagen aterradora del cadáver de la mujer blanca, no supone la real apertura de una conciencia que problematiza racionalmente las condiciones de la traición y la acepta bajo sus premisas después de una reflexión interiorizada. Si tenemos en cuenta que estamos ante un niño y que este niño se ve presionado a otorgar el perdón debido al horror de la muerte, puede concluirse que el cuento apuesta por precipitar violentamente al niño en la culpa y a su descenso al espacio en donde radica el mal sin permitírsele una explicación de lo sucedido. Si bien esta caída supone un cuestionamiento a la moral y a las costumbres burguesas, este se da desde lo no racional, desde la clausura de la razón.

Con respecto al segundo elemento, es claro que el suicidio de Luisa/la mujer blanca confirma un elemento central en el decadentismo: el heroísmo individual y sin posibilidades de tener esperanza, esto es, el estado de disyunción absoluto del sujeto con su objeto de valor (el perdón), estado que, como consecuencia de la primera disyunción, termina por convertir a 
su propia vida en un objeto sin valor. Este personaje femenino representa la pérdida de sentido, la negación de un mundo que se resiste a comprender la naturaleza de su comportamiento y que la conduce a la autodestrucción.

\section{CONCLUSIONES}

1. "Los ojos de Judas" se inscribe dentro del decadentismo narrativo, pero mantiene ciertos elementos de la poética criollista tales como la presencia de lo local-provinciano y la descripción de ambientes (la aldea de Pisco) y festividades tradicionales (Semana Santa).

2. La contradictoria situación en la que se desarrolla el conflicto central: la traición de Luisa, sirve al propósito de crear una atmósfera en donde se busca, a su vez, algo contradictorio para un creyente en el cristianismo: el perdón para Judas.

3. El carácter irrealista del cuento, manifestado desde la difusa presencia de la mujer blanca, incide en la confusión de los sentidos que sirve para la exploración de una sensibilidad materna en crisis que busca para sí misma el perdón. Este carácter irrealista se ve reforzado por la construcción de un arquetipo antiheroico de la madre suicida.

4. La orilla es el espacio privilegiado en el cuento y se constituye en una franja intermedia en donde tienen lugar la realización de lo onírico o los llamados desarreglos de los sentidos. Gracias al espacio de la orilla el cuento puede acceder a lo inefable de la experiencia.

5. La fidelidad marital, la unión familiar y la maternidad son representados a partir de situaciones que ponen en riesgo su condición de valores o producen su destrucción. Esta experiencia de los límites genera performances que conducen a los personajes a aceptar el mal.

6. El extrañamiento de la realidad es un recurso que desvincula al personaje narrador de su entorno y apoya la creación de una atmósfera inquietante, de inseguridad general en donde todo se presenta como afectado por fuerzas ocultas e ingobernables.

7. La libertad para experimentar literariamente con el mal se corresponde con la absoluta libertad del escritor para expresar su experiencia de lo abismal en el contexto del modernismo decadentista. 


\section{REFERENCIAS}

Ahern, M. (1960). “Mar, magia y misterio en Valdelomar”. Sphink, 13, 151-169. Bernabé, M. (2006). “Dandismo y rebeldía en el Perú: el caso de Abraham Valdelomar en Vidas de artista. Bohemia y dandismo en Mariátegui, Valdelomar y Eguren (Lima, 1911-1922). Lima: Instituto de Estudios Peruanos, 41-63.

Valdelomar, A. (2001). Obras completas. 4 tomos. Edición de Ricardo Silva Santisteban. Lima: Ediciones Copé.

. (2013). Cuentos completos. Edición de Ricardo Silva Santisteban. Lima: Estruendomudo. 